\title{
O MUSEU NA SALA DE AULA: propostas para o planejamento de visitas aos museus
}

\author{
Ricardo de Aguiar Pacheco*
}

\section{Resumo}

Tendo por base a análise de dados empíricos de uma série de atividades de ensino em espaços museológicos, o presente artigo sistematiza uma série de elementos que orientam o uso dos museus no ensino de história. Propomos uma metodologia para um uso didático do museu na sala de aula que preveja, primeiro, a vinculação dos conteúdos estudados em sala de aula à exposição que será visitada; segundo, a realização da visita de forma articulada com uma programação definida e; terceiro, de volta a sala de aula, a utilização da experiência vivida no museu para a realização de uma produção cultural.

Palavras-chave: Ensino de história. Museu. Planejamento de ensino.

\section{THE MUSEUM IN THE CLASSROOM: educational planning with museums}

\begin{abstract}
Based on the analysis of empirical data from a series of educational activities in museum spaces, this article explores a series of factors which guide the use of museums in teaching history. We propose a methodology for a didactic use of the museum in the classroom that allows, first, the linking of the contents studied in the classroom with the exposure to be visited, and second, the realization of the visit jointly with a set schedule and, third, back to the classroom, the use of the museum experience to conduct a cultural product.
\end{abstract}

Keywords: Teaching history. Museum. Teaching planning.

Para a maioria dos professores, conduzir uma turma de escola ao museu é uma aventura. Uma operação que demanda um esforço de organização e uma disposição para

\footnotetext{
* Doutor em História pela Universidade Federal do Rio Grande do Sul. Professor da Universidade Federal Rural de Pernambuco. E-mail: pacheco_ricardo@yahoo.com.br
} 
encontrar soluções que já demoveu a muitos. Providenciar agenda no museu, viabilizar o transporte, solicitar as autorizações das famílias, da direção da escola, enfim, uma série de ações que todo o professor gostaria que já estivesse resolvida para que pudéssemos pensar apenas nos conteúdos de ensino. Reconhecendo o valor de quem realiza essa parte operacional, nosso desejo aqui é justamente discutir a parte do planejamento didático que dá sentido educacional a visita ao museu. Queremos destacar alguns conteúdos e procedimentos que podem ser explorados na disciplina escolar de história como forma de não apenas levar os alunos ao museu, mas também trazer as informações e aprendizagens da visita ao museu para a sala de aula de história. Ou seja, nos interessa a vinculação das informações disponíveis no museu, das experiências vividas pelos alunos, das habilidades desenvolvidas com as atividades da sala de aula.

Para discutirmos a relação dos museus com a sala de aula temos de entender, antes de tudo, que os museus sempre foram pensados como instituições de ensino. Locais onde se acessa um conjunto de objetos com a intenção de obter informações sobre determinado tema ou assunto. A definição proposta pela Comissão Internacional de Museus (ICOM) nos diz que:

\begin{abstract}
“Os museus preservam a propriedade cultural mundial e interpretam-na ao público. [...] Faz parte do patrimônio natural e cultural mundial e pode ser de caráter tangível ou intangível. Muitas vezes, o bem cultural providencia também a referência primária em vários temas da área, tais como arqueologia e ciências naturais, e por isso representa uma contribuição importante para o conhecimento. É também, um componente significativo na definição da identidade cultural, a nível nacional e internacional.” (LEWIS, 2004, p. 1)
\end{abstract}

Acompanhando Francisco Ramos (2004), o entendemos como um lugar onde é possível observar objetos culturais (materiais e imateriais) e se apropriar das informações que eles materializam. É, portanto, é um lugar para se viver uma experiência sensível. Sendo lugares de aprendizagem, são também espaços de lazer onde se compartilham sensações e emoções e uma dimensão não deveria eliminar a outra.

A ideia de museu tem sua origem no desejo humano de colecionar objetos, de reunir, classificar e expor coisas diversas. Françoise Choay (2006) nos aponta que desde tempos remotos que a humanidade desenvolve estratégias para guardar e reunir objetos e explorar as informações que eles carregam. Foi reunindo objetos que os antigos gregos criaram o museon, o tempo das musas gregas. Na Era Moderna surgiram os gabinetes de curiosidades onde se reunia coleções de objetos e curiosidades de diferentes partes do mundo. É a partir do século 
XVIII que os estados nacionais passam subvencionar e expor coleções voltadas ao público geral. Atualmente museus são instituições internacionalmente reconhecidas como lugares que ensinam seus visitantes na medida em lhes propõe uma relação com os objetos expostos.

\begin{abstract}
“As mudanças do significado de museu através dos tempos talvez possam ser compreendidas como uma trajetória entre a abertura de coleções privadas à visitação pública ao surgimento dos museus na acepção moderna, como instituições a serviço do público. Concebidos com a função de educar o povo desde a Revolução Francesa, os museus, [...] Como em nenhuma outra época, o papel educativo e a relação do museu com a comunidade tornam-se, de fato, questões nucleares do pensamento e de práticas museológicas.” (JULIÃO, 2006, p. 29)
\end{abstract}

Os museus sempre carregaram a intenção de educar. Seja no sentido estrito de transmitir informações, próprio das concepções tradicionais de educação, seja no sentido amplo de construir identidades, visão de educação defendida pelos educadores críticos e póscríticos (SILVA, 1999). Do ponto de vista pedagógico o museu é o local onde se realiza tanto a pesquisa sistemática sobre o assunto que ele expõe como o espaço de sensibilização do público para determinados temas e assuntos. Do ponto de vista didático o museu serve tanto ao ensino dos conteúdos factuais, possibilitando a coleta e sistematização de informações pontuais, como aponta para o desenvolvimento das habilidades e da sensibilidade de cada visitante.

O senso comum define, erroneamente, o museu como lugar de coisas velhas, lugar de coisas do passado e, de forma mais equivocada, todos os outros tipos de museus são confundidos com este. No senso comum, se esquece, primeiro, que existem museus voltados a diferentes temas e, segundo, que os museus se modernizam incorporando novas linguagens, tecnologias da informação e equipamentos que os tornam mais dinâmicos ativos e atrativos. Os museus de história se dedicam a exposição de objetos e temas do passado, mas existem coleções ligadas a outras disciplinas e assuntos que também podem ser explorados nas aulas de história. Os museus antropológicos são dedicados a grupos humanos e suas produções; os museus de ciências estão voltados à exibição de fenômenos e propriedades científicas; os museus de arte se dedicam a produção plástica do passado e do presente. Estes espaços, que não são museus históricos em sentido estrito, podem ser utilizados nas aulas de história. Como nos destaca Ulpiano de Menezes, para exploramos a dimensão histórica de uma exposição temos de destacar os elementos e dados históricos dos objetos, orientando a percepção da dimensão temporal do tema em exposição. 
“A exposição verdadeiramente histórica é aquela em que a comunicação dos documentos, por sua seleção e agenciamento, permite encaminhar inferências sobre o passado - ou melhor, sobre a dinâmica - da sociedade, sob aspectos delimitados, que conviria bem definir, a partir de problemas históricos. Inferências são abstrações, que não emanam da materialidade dos objetos, mas dos argumentos dos historiadores, referindo-se a propriedades materiais ‘indiciárias' desses objetos e a informações sobre suas trajetórias.” (MENEZES, 1994, p. 39)

Pierre Nora argumenta que diferentes lugares - entre eles os museus de história - se constituem em lugares de memória porque assumem a tarefa de difundir determinada versão dos eventos do passado na memória coletiva de uma comunidade. "São lugares, com efeito, nos três sentidos da palavra, material, simbólico e funcional, simultaneamente, somente em graus diversos.” (Nora, 1993, 21). Neste argumento entende-se que os museus - não apenas os de história - são materialidades que tem a funcionalidade de produzir uma simbologia sobre a dimensão temporal, seja o tempo físico (Piaget, 2002), seja o tempo histórico (Rusen, 2001; Hartog, 2006); no que toca ao ensino de história em museus podemos dizer que entre os temas de interesse estejam, entre outros, os eventos históricos, o tempo histórico e a memória social.

Os museus também se diferenciam quanto à sua forma de organização. Inúmeros museus ainda se mantêm como um gabinete de curiosidades reunindo um conjunto de itens mais ou menos conexos entre si. Este é o caso típico do museu da cidade pequena que, formado e mantido por iniciativa individual, reúne um acervo de objetos diversos, agrupados mais pela perseverança que por uma lógica interna a coleção. Outros museus ainda trazem as marcas dos discursos nacionalistas e se empenham em destacar o 'maior isso', o 'mais aquilo' de cada lugar. Já os museus mais recentes estão carregados de tecnologia, luzes e som atrativos que mobilizam da atenção do visitante. Todos eles, contudo, podem ser utilizados pelo professor de história com o mesmo sentido: educar para a percepção da aventura humana no tempo por meio do contato com o objeto.

\footnotetext{
"O museu é um ambiente educativo peculiar. Ele tem um acervo de registros selecionados da vivência sócio-histórica. Ele tem, afinal, materialidade e oportunidades de simbolização não encontradas na escola. E é a partir de uma educação para olhar através dessa materialidade (dispersa, contraditória, lacunar e plural) que se realiza seu papel educador, sua peculiaridade e sua potencialidade.” (SIMAM, et ali, 2007, p. 37)
}

Já existem algumas propostas sistematizadas sobre como explorar de forma didática os museus e suas exposições. Entre estas podemos destacar a Metodologia da Educação 
Patrimonial, divulgada por Maria de Lourdes Horta (1999), e a Metodologia Triangular, descrita por Ana Mae Barbosa (1995). Correndo o risco das simplificações podemos dizer que a educação patrimonial consiste em educar por meio do estudo do objeto cultural musealizado. Ela propõe uma metodologia de quatro etapas: a observação direta do objeto, o registro das informações oferecidas pelo objeto, exploração em outras fontes sobre informações complementares sobre o objeto e, finalmente, a significação do objeto por parte do sujeito da ação educativa. Esta abordagem é referência, por diversos autores que tratam o ensino de história como Circe Bittenourt (2004) e Kátia Maria Abud (2010), e se constitui em leitura obrigatória para se pensar as ações educativas centradas nos bens culturais desenvolvidas dentro ou fora do espaço do museu.

"A metodologia específica da educação patrimonial pode ser aplicada a qualquer evidência material ou manifestação da cultura, seja um objeto ou um conjunto de bens, um monumento ou um sítio histórico ou arqueológico, uma paisagem natural, um parque ou uma área de proteção ambiental, um centro histórico urbano ou uma comunidade da área rural (...)” (HORTA, 1999, p. 6)

Já a metodologia triangular foi formulada por Ana Maria Barbosa (1995) tem sua origem nos dos museus de arte. Ela está focada no desenvolvimento da sensibilidade e na fruição da obra. E faz isso buscando localizar a peça na história da arte, no contexto histórico de criação do autor. Esta metodologia, de maneira muito sintética, propõe três tipos de ações: a livre leitura e interpretação da obra pelo público; o estudo e o debate sobre o momento histórico de sua produção; e a releitura da obra por meio da produção de outra obra por parte do sujeito que está vivendo a ação educativa.

\footnotetext{
"Em arte-educação a Proposta Triangular, que até pode ser considerada simplificadora comparada com os parâmetros das nações centrais, tem correspondido à realidade do professor que temos e à necessidade de instrumentalizar o aluno para o momento em que vivemos, respondendo ao valor fundamental a ser buscado em nossa educação: a leitura, a alfabetização.” (BARBOSA, 1995, p. 63)
}

Reconhecendo a importância destas metodologias para as atividades educativas desenvolvidas no interior dos museus, desejamos aqui refletir sobre o uso dos bens culturais musealizados 'na' escola. Ou seja, nos interessa discutir não apenas o momento da visitação, mas o momento anterior, quando se mobiliza a atenção dos estudantes para a atividade, e o momento posterior quando, na escola, o professor se utiliza da experiência vivida no espaço 
museal para realizar outras atividades didáticas. Por isso propomos que o planejamento para o uso didático do museu na sala de aula deve estar atento e prever, inicialmente, a vinculação dos conteúdos estudados à exposição que será visitada, segundo, a realização da visita com uma programação definida e, de volta à sala de aula, a utilização da experiência vivida no museu para a realização de uma produção cultural.

Sabemos que a didática não pode ser pensada como "a arte de ensinar tudo a todos" como propôs Comênico (2006) em um passado e, portanto, como alerta Vera Candau (1984) não nos propomos a ser prescritivos de ações didáticas previamente concebidas a revelia do espaço social em que serão desenvolvidas as ações pedagógicas. Na outra margem, entendemos, como José Carlos Libâneo (1990) e Antoni Zabala (1998), que a reflexão sobre a experiência docente pode - e deve - reorientar o planejamento da prática pedagógica com vistas a qualificar a relação ensino-aprendizagem. Com estes parâmetros estamos aqui sistematizando um conjunto de orientações gerais construídas ao longo de diferentes ações didáticas vividas em diferentes espaços museais. Estas ações foram desenvolvidas primeiramente como professor da educação básica, depois como professor da disciplina de Prática de Ensino em História e, mais recentemente, como orientador de bolsistas de Iniciação à Docência que tematizam as relações escola-museu.

Ao longo de anos temos desenvolvido diversas atividades de ensino que envolvem escola e museu dando origem a estudos que descrevem e analisam experiências específicas (Pacheco, 2010a, 2010b, 2012). O passo que damos nesse momento é a busca de uma síntese desses diferentes estudos anteriores e a configuração de um roteiro que não se pretende prescritivo, mas que, fruto da reflexão sobre a prática pedagógica, seja útil ao planejamento e a reflexão de outras atividades que envolvem escola e museus. As indicações e generalizações que seguem não evitam o surgimento de problemas na execução da atividade, mas permite nos anteciparmos para procurar soluções e assim gerenciá-los de forma mais racional.

\section{Um planejamento de três tempos}

Para utilizarmos o museu em sala de aula é preciso ter em mente que a visita se inicia muito antes do professor e seus alunos chegarem ao museu. E se estende para além deste momento. Acreditamos que a qualidade da atividade e seu significado pedagógico dependem 
da qualidade do cuidado do professor no momento do planejamento da atividade. É esta previsão das ações que direciona a atenção dos alunos para as atividades didáticas e potencializa o impacto da experiência vivida para o aluno.

Não é incomum as escolas planejarem visitas a museus como momentos de lazer para os alunos, momentos em que o professor solta os alunos na porta do museu e os esquece. Visitas promovidas com a finalidade de confraternização de fim de ano letivo ou mesmo premiação de alguma gincana são legítimas, mas não garantem a aprendizagem de saberes significativos ao aluno. Podemos dizer que estes são os chamados 'passeios', momentos em que tanto professores como alunos desejam que não exista a obrigação de realizar qualquer aprendizado formal. De outra parte, também é usual professores proporem aos alunos a ida ao museu como uma 'atividade de campo', como o momento em que, de caneta em punho, cada estudante deve anotar tudo o que ver e ouvir para engrossar o relatório escrito que será entregue na aula seguinte. Atividades neste formato são interessantes, mas no mais das vezes produzem uma massa muito grande de informações que acabam não sendo sistematizadas pelo aluno.

Não vemos grandes problemas com estas nomeações: passeio, atividade de campo, ou qualquer que seja o nome dado a atividade no museu. Contudo, aqui propomos que ela seja considerada como a 'visita' que fazemos a casa de uma pessoa que não é um total estranho, mas que também não é alguém de todo íntimo. Podemos propor aos alunos que a atividade seja comparada a visita que fazemos a uma tia distante que vemos apenas uma vez por ano. Ou seja, nada tão solene que nos deixe constrangido, mas também nada tão normal que deixe de ser um evento especial. Inúmeros museus históricos estão instalados em casa de alguma personalidade que mesmo não estando vivo pode ser tido como nosso anfitrião. Esse é o caso, por exemplo, do Museu Imperial em Petrópolis que foi residência de verão da família real brasileira.

A confecção de um bom planejamento se inicia com a visita prévia do professor ao museu. É importante que o professor conheça o local e reconheça as possibilidades de atividades a serem desenvolvidas. Estude a exposição que está sendo oferecida pelo museu e converse com o setor educativo da instituição. A maioria dos museus mantém um serviço educativo que orienta os professores sobre como o museu pode ser explorado. Bons exemplos deste trabalho são o Museu do Ipiranga (São Paulo, SP) e o Museu do Homem do Nordeste (Recife, PE). Somente assim o professor poderá verificar que opções de atividades são oferecidas e até mesmo criar ações que sejam mais interessantes aos seus alunos e aos 
conteúdos que estão sendo trabalhados em sala de aula. Libâneo (2008) destaca o significado político-pedagógico do ato de planejar a ação educativa afirmando que:

“O planejamento é um processo de racionalização, organização e coordenação da ação docente, articulando a atividade escolar e a problemática do contexto social. [...] A ação de planejar, portanto, não se reduz ao simples preenchimento de formulários para controle administrativo; é, antes, a atividade consciente de previsão das ações docentes, fundamentadas em opções político-pedagógicas, e tendo como referência permanente as situações didáticas concretas” (LIBÂNEO, 2008, p. 222)

Ao planejar a exploração didática de uma exposição museológica, devemos pensá-la como um texto escrito com objetos. E considerar que este texto pode ser lido e interpretado de diferentes formas, com diferentes ênfases. O professor, para realizar um planejamento adequado ao espaço museal visitado, não pode deixar de fazer a sua leitura deste texto de objetos para apresentá-la e debatê-la com os alunos ao longo da atividade.

\footnotetext{
"Esta questão enfoca a museologia enquanto disciplina voltada para o estudo da referência patrimonial objetivando transformar o objeto-testemunho em objeto-diálogo. Nesse sentido, as exposições vêm sendo repensadas no âmbito de uma estrutura de comunicação através de propostas museológicas definidas, que utilizam uma linguagem compreensível e de fácil acesso aos visitantes.” (ALMEIDA \& VASCONCELOS, 1997, p. 106.)
}

Museus costumam ter uma exposição permanente (ou de longa duração) e outra exposição temporária (que são trocadas com certa frequência). Outros têm exposições extensas e por isso divididas em partes com salas abordando temas diferentes. Todas estas possíveis divisões de uma exposição podem ser tratadas como se fossem capítulos de um mesmo livro. E um livro que não precisa ser lido integralmente em uma única visita. Mesmo que a turma seja conduzida por todo o espaço do museu é possível planejar quais as partes da exposição, quais os temas serão de fato objeto de atenção da atividade didática. Ou seja, não é por que a exposição de museu apresenta duzentos objetos que o relatório de visita deve relatar cada um deles. Do outro lado, não é responsabilidade do aluno, por seu próprio critério, escolher o objeto mais interessante para descrever apenas este. Entendemos que cabe ao professor, no seu planejamento, estabelecer o tema da visita, definir o tipo de informações que interessam para o estudo que a turma esta desenvolvendo em sala de aula e definir previamente as ações que serão solicitadas aos alunos.

Imaginemos uma visita ao Museu Histórico Nacional (Rio de Janeiro, RJ) ou ao Museu Imperial (Petrópolis, RJ) que possuem, cada um, mais de 15 espaços temáticos para 
serem explorados. têm uma exposição muito rica e ampla apresentando objetos de diferentes períodos históricos e relacionados a diversos grupos sociais e suas atividades. Para que a visita não se torne cansativa é recomendável que o professor defina previamente quais elementos serão focados na atividade didática. A visitação também pode ser focada e explorada em apenas algumas salas para que o volume de informação da exposição não dificulte o entendimento do tema que está sendo estudado.

No momento de agendar a visita é possível estabelecer uma rápida conversa com o setor educativo do museu e obter respostas para algumas questões importantes para o planejamento da visita: o museu dispõe de mediadores que recebem os alunos ou o professor fará a condução da turma? Estes mediadores fazem adequações a temas específicos ou existe apenas um roteiro fixo de visitação? O museu já oferece alguma atividade educativa posterior a visita? Existe um espaço diferenciado para atividades didáticas do professor? Estas e outras questões são rapidamente esclarecidas em conversa prévia e podem evitar inúmeros atropelos e desentendimentos no momento da atividade no museu.

O professor também deve observar o espaço global e o entorno do museu. Existe um local adequado para realizar o lanche e o momento de lazer da turma? A área do museu conta com uma lanchonete ou loja de lembranças? O local onde a turma irá desembarcar exige algum cuidado especial como atravessar a rua ou dobrar uma esquina? Saber destas condições oferecidas permite ao professor tomar decisões no momento do planejamento que irão fazer a diferença na execução da atividade. A localização de algumas instituições, como o Museu do Mamulengo situado no Sítio Histórico de Olinda, PE, não permite que o ônibus deixe a turma na entrada do prédio. Assim é preciso planejar o trajeto a caminhar com as crianças. Por outro lado, este mesmo museu dispõe de um pátio interno que é franqueado aos grupos de estudantes para fazer o lanche e brincar livremente. Da forma semelhante, outros museus situados em vias de grande movimentação, como o Museu de Arte de São Paulo, localizado em plena Av. Paulista, ou o Museu Júlio de Castilhos (Porto Alegre, RS) requerem cuidados adicionais no momento de desembarque e embarque dos estudantes que devem ser pensados com antecedência.

Com esse diagnóstico inicial é preciso planejar uma sequência didática que preveja três momentos: a inserção do tema da exposição a ser visitada no programa da disciplina e a construção de um instrumento de registro da visita; a visita em si para a coleta de informações sobre o tema estudado; o uso das informações do museu em sala de aula para aprofundamento do tema estudado e a confecção de um produto final. Estes momentos devem estar ligados por uma atividade a ser desenvolvida sucessivamente nos diferentes momentos e espaços. Ou 
seja, é preciso trazer o museu para a sala de aula, levar os assuntos de aula para o museu e retornar a sala com as informações e impressões da visita.

\section{As atividades anteriores}

Uma visita ao museu é sempre uma atividade motivadora para a turma. Os alunos invariavelmente ficam agitados com a possibilidade de sair da escola e realizar um 'passeio', com a possibilidade da realização de uma 'não aula', de um momento em que não será preciso estudar. O professor não precisa concordar com essa primeira intenção dos alunos, mas também não precisa contrariá-los ou desiludi-los com ameaças que não está disposto a cumprir ou tarefas imensas que não tem disposição para corrigir. Ao contrário, propomos que o interesse dos alunos seja mobilizado na direção de ajudar na própria organização da atividade. Isso pode ser feito de diferentes formas: Alunos pequenos, do primeiro ciclo do ensino fundamental, podem ser mobilizados para confeccionarem os crachás de identificação com seus nomes, nome da escola, nome e telefone da professora. Alunos maiores podem ser mobilizados com a produção das listas de passageiros que devem ser entregues ao motorista do ônibus e à recepção do museu. Alunos do ensino médio podem ser divididos em comissões que assumam diferentes tarefas para a operacionalização da atividade: orçamento do ônibus, arrecadação, lanche... O importante nesta visão é reservar momentos em sala de aula para realizar estas tarefas, no caso dos menores, ou para verificar o andamento de tarefas extraclasse. Assim como é importante o professor reconhecer que esta capacidade de organização da atividade já representa um aprendizado sócio-histórico, um aprendizado sobre como os grupos sociais percebem e se organizam para a realização de trabalhos coletivos e como cada indivíduo se organiza na dimensão temporal (Rusen, 2001; Hartog, 2006).

Mas também é preciso deixar muito claro com a turma qual será o foco da atividade. Para isso é importante que a visita ao museu esteja articula com as atividades didáticas ocorridas em sala de aula, com os conteúdos que estão sendo estudados no período da visita. Uma vez anunciada e marcada a data da visita ao museu o professor poderá direcionar suas aulas para temas que serão vistos na exposição fazendo uso de frases como "poderemos ver objetos como este na visita ao museu” ou "no museu que vamos visitar existem peças relacionadas a esse assunto”. Frases assim servem tanto para o reforço do conteúdo a ser estudado como para produzir lentamente nos alunos a percepção que a visita não será apenas para diversão. O que certamente aumentará o grau de comprometimento dos alunos na atividade. 


\begin{abstract}
“Com atividades vinculadas à 'historicidade dos objetos' na própria sala de aula, o professor incita a percepção dos alunos e ai eles terão o direito de saborear, com mais intensidade, as propostas de reflexão oferecidas pelo museu. Desse modo, não se trata mais de 'visitar o passado', e sim de animar estudos sobre o tempo pretérito, em relação com o que é vivido no presente. Com a excitação para a aventura de conhecer através de perguntas sobre os objetos, abre-se espaço para a percepção mais ampla diante da exposição museológica. Mais que isso: alarga-se o juízo crítico sobre o mundo que nos rodeia.” (RAMOS, 2004, p. 24)
\end{abstract}

Desta forma propomos que na sala de aula, antes da visita ao museu, a turma seja mobilizada com indagações, questões, debates que requeiram informações disponíveis na exposição. O planejamento da visita deve definir os conteúdos a ser explorados na visita. Temas como os objetos da vida cotidiana de um determinado período ou local, os instrumentos de trabalho de determinada atividade econômica. E os conceitos articuladores destes objetos, como cotidiano e trabalho. Neste momento é interessante utilizar recursos convencionais, como livros didáticos e materiais de divulgação do próprio museu, como cartazes e panfletos. Diversos museus mantêm páginas de internet onde é possível visualizar detalhes da exposição e que também podem ser explorados nesta preparação da visita. Todos estes movimentos têm como objetivo levar o aluno a reconhecer o museu como espaço para a descoberta de novas informações.

Para que a exposição seja vista e explorada como fonte de informação é preciso definir com os alunos a forma de registro que será feito durante a visitação. O instrumento mais utilizado para isso é o relatório: texto extenso onde se descreve a maior quantidade de informações coletadas na visita, sem a necessidade de articular estes dados entre si ou com as informações das aulas anteriores. Trabalho cansativo, tanto para o aluno que realizar como para o professor que deve corrigir. Por ser muito abrangente também facilita que o aluno não relacione a visita com o conteúdo que está sendo trabalhado em sala de aula. Por isso é importante que no momento da proposição do relatório seja recortado um foco, um ou mais temas a serem explorados no texto.

Outra ferramenta tradicional é a ficha de observação. Comumente este instrumento é construído e distribuído pelo professor na chegada do museu. Lembramos que as fichas de observação podem ser construídas em aula com a turma definindo que dados interessa coletar no museu visitado. Nessa construção coletiva o professor deve cuidar para incluir itens que interessam ao assunto estudado. É importante o professor ter presente que dados estão disponíveis nas peças em exposição, mas também pensar que incluir perguntas que não serão 
respondidas com a visita pode desencadear novas pesquisas. Um planejamento sobre escravidão na exposição no Museu do Homem do Nordeste (Recife, PE) pode solicitar a identificação e o registro apenas de objetos que estejam ligados ao trabalho escravo e não de todos os objetos. Um planejamento sobre a Independência no Museu do Ipiranga (São Paulo, SP) pode solicitar o registro apenas dos quadros históricos da exposição permanente. Já um planejamento sobre a história da cidade em qualquer museu municipal pode pedir aos alunos que associem um número de objetos a cada momento da evolução deste núcleo urbano. Nestes casos a primeira tarefa dos alunos durante a visita é relacionar os objetos da exposição ao conteúdo estudado em sala de aula e somente depois dessa tarefa realizar o registro.

Mas é possível propor que os registros sejam feitos por meio de desenhos seguindo a estratégia da releitura dos objetos culturais. Também é possível propor o uso de câmeras fotográficas sem flash (disponíveis em boa parte dos telefones celulares). A visita a sítios históricos, museus a céu aberto, como as Reduções Jesuíticas (Santo Ângelo, RS) ou a cidades históricas, como Ouro Preto, MG e suas igrejas, dispõem de amplos espaços onde os alunos podem fazer poses e mesmo encenar determinadas situações históricas para serem fotografadas. Também é possível solicitar que sejam fotografados os diversos momentos da visita: a saída da escola, o seu retorno, a chegada ao museu, o percurso da exposição. Enfim, é importante lembrar que a escrita é apenas uma das múltiplas linguagens disponíveis para a comunicação e para o estudo da história.

Uma atividade interessante é, na aula imediatamente anterior a visita, repassar com a turma o cronograma da atividade anotando no quadro e nos cadernos os horários combinados para cada atividade: a hora do encontro na escola, a hora da saída do ônibus, o tempo de viagem, a hora de chegada ao museu, que ações e cuidados serão necessários no desembarque (atravessar a rua, dobrar uma esquina, esperar o grupo se reunir na porta de entrada do museu...), combinar o horário e o local em que será feito o lanche coletivo, se haverá alguma atividade complementar a visita e, por fim, o horário e os procedimentos para o retorno. Este roteiro pode ser construído na forma de uma linha de tempo com duas finalidades: uma prática outra de conteúdo. No sentido prático destacamos que quanto mais claro e detalhado for este roteiro, mais seguros e tranquilos ficarão os alunos em relação ao que vai acontecer reduzindo assim a tensão natural em uma atividade fora da escola. Noutro sentido, a confecção deste roteiro permite trabalhar com os alunos a noção de tempo e de processo histórico, pois a descrição das ações pretendidas e sua posterior realização (ou não) permitem a reflexão coletiva sobre a dimensão temporal e as estratégias utilizadas para representá-lo, como a linha de tempo e o roteiro de viagem. 
Por fim, não importa qual desses registros seja utilizado, é importante combinar com a turma, antes da visita, a confecção de um produto final para o momento posterior a visita. $\mathrm{O}$ museu se fundamenta no estudo materialidade dos objetos - tangíveis ou intangíveis - e nada mais natural que utilizar a materialidade para finalizar a atividade. Lembre que o produto final deve estar associado à forma de registro proposta. Ao solicitar a produção de relatórios teremos como produto final a entrega destes relatórios. Já as fichas de registro podem ser transformadas em um catálogo da exposição. As fotografias podem formar painéis que remetam aos diferentes momentos e aspectos da visita.

\section{$A$ visita em si}

Então é hora da vista. Invariavelmente esse momento não acontece exatamente como foi planejado. Isso não é motivo para não realizarmos o planejamento, lembre que sem o planejamento estaríamos menos preparados para os imprevistos. O conjunto de reflexões que foram feitos, no momento da formalização e da escrita do plano, nos apontou possíveis falhas e nos permitiu pensar com antecedência como resolvê-las. Assim se o ônibus atrasou, já se havia marcado sair mais cedo; se um aluno não trouxe a autorização, ele ficará na escola com uma atividade diferenciada já preparada; se o monitor não atender as expectativas da turma o professor já tem informações básicas sobre o tema da exposição e sobre os conteúdos que deseja destacar.

Chegando ao museu o primeiro passo, como deve ter sido previsto no roteiro feito com a turma, é sempre reunir o grupo em um local próximo ao ônibus e somente depois ir, em grupo, para a entrada do museu. Não é aconselhável que os alunos já desembarquem no local se dispersem tão pouco que entrem diretamente no espaço de exposição.

É recomendável que o professor que fez a reserva procure a recepção, confirme o agendamento e espere as instruções. Cada museu tem uma rotina de recepção, mas elas passam, via de regra, pela indicação de um mediador que irá acompanhar o grupo. É importante que o professor converse rapidamente com esse mediador retomando o assunto que a turma está estudando, e o que espera que seja destacado na visita, bem como descreva brevemente o perfil da turma. Estas informações simples são essenciais para o mediador definir suas ações e possibilitar uma visita mais prazerosa e proveitosa. Outro cuidado é o próprio professor fazer a apresentação do monitor à turma.

É comum os professores se afastarem da turma durante a visitação, mas isso tem duas implicações negativas: primeiro sobrecarrega o mediador que não tem a responsabilidade de 
resolver corriqueiras questões disciplinares; segundo ao se afastar o professor, como modelo, demonstra aos estudantes que acompanhar a atividade não é importante. Assim é sempre recomendável que o professor responsável pela atividade acompanhe os alunos ao longo da visitação.

Como combinado anteriormente os alunos devem produzir registros da visita. É importante também que o professor acompanhe a realização destes registros. Um pouco para garantir a realização da atividade e muito para perceber a qualidade deles, lembrando que estas informações serão utilizadas nas aulas posteriores. Observações de atividades em museus apontam que turmas bem preparadas estarão mais motivadas para a visita, realizando perguntas, fazendo anotações em suas fichas, realizando fotos dos objetos e do espaço. Ou seja, fazendo da visita realmente um momento de estudo. Ao passo que turmas deixadas na exposição sem acompanhamento se dispersão rapidamente não aproveitando as informações disponíveis.

\begin{abstract}
“A bagagem cultural que o aluno traz fornece os elementos essenciais para a 'descoberta do objeto'. Esta se faz pela utilização de um método que obedece a etapas distintas, mas não rígidas, por dependerem de variáveis como tipo de museu, presença ou não de monitores, temática, tempo disponível para a visita, entre outras. O princípio básico do método de investigação de objetos reside na observação livre e na observação dirigida. Com a observação pretende-se que o aluno aprenda a 'ver', seja capaz de parar diante de um objeto, fixar e concentrar o olhar sobre ele." (BITTENCOURT, 2004, p. 358)
\end{abstract}

Não podemos esquecer que a visita ao museu também é um passeio, também deve ser divertida para os alunos. Julgamos que a melhor forma de evitar que os alunos se dispersem durante a visita ao museu e deixem de acompanhar a atividade é combinar com eles antecipadamente o local e o momento da confraternização. Assim cada aluno passa a esperar por este momento que, para eles, é o mais importante do passeio: a hora do recreio. É interessante que o professor participe deste momento se integrando ao grupo e também se divertindo. Locais como o Museu Regional de Olinda (Olinda, PE) dispõem de um pátio interno lindamente arborizado e ajardinado que é oferecido aos professores para a realização do lanche. Espaços mais modernos como o Museu do Futebol (São Paulo, SP) possuem bares no seu entorno e a permissão para o uso desses espaços deve ser bem ponderada.

Instituições como o Museu do Ceará (Fortaleza, CE) têm atividades especiais para a serem oferecidas aos alunos no momento posterior a visita tais como oficinas de desenho ou jogos relativos à própria exposição. Caso isso não exista é possível o professor propor uma 
dinâmica, uma brincadeira possível de ser realizada pelo grupo no espaço disponível ou no pátio do museu. Papel e lápis de cor são recursos suficientes para a realização de atividades simples como a produção de um texto ou de um desenho alusivo a exposição. Lugares como o Museu da Abolição (Recife, PE) possuem um amplo pátio onde é possível brincar de pegapega, mas o mais recomendado são jogos de roda e dinâmicas de atenção como adoleta, jogo de mímicas ou de perguntas e respostas sobre os objetos expostos.

\section{As atividades posteriores}

Não é incomum os professores encerrarem as atividades com a entrega do relatório na aula seguinte. Contudo, acreditamos que a experiência de visitar um museu é muito significativa para se encerrar desta forma simplificada.

Segundo Katia Abud “A volta para a escola não precisa pôr fim à experiência da visita ao museu. Pelo contrário, esse é um momento em que os alunos explicitam questões, dúvidas, curiosidades.” (Abud, 2010, p. 143). No mesmo sentido, Selva Fonseca argumenta que “A discussão e a sistematização dos conteúdos após a visita proporcionam o diálogo entre diferentes fontes que falam o mesmo tema, como, por exemplo, os textos didáticos, as imagens, as roupas, os objetos, as cartas etc.” (Fonseca, 2003, p. 230)

Da mesma forma propomos que a visita ao museu deve ser aprofundada na aula seguinte. Para isso devem se utilizados os registros feitos durante a visita. É com base neles que o museu e seus objetos voltam à sala de aula. Agora como fonte de informação para aprofundar o assunto estudado pela turma. Ou seja, utilizando as informações recolhidas pelos alunos no museu é possível complementar as informações disponíveis nos recursos didáticos já utilizados em sala de aula, como aulas expositivas, livros didáticos e internet.

Tomando por base as atividades que exemplificamos anteriormente apontamos que uma primeira atividade a ser desenvolvida é a retomada da linha de tempo do roteiro produzido com a turma na aula anterior a visita. Essa atividade pode estar focada na percepção da dimensão temporal, na explicitação do tempo como dimensão social na qual os eventos históricos se realizam (ou não) da forma como foi planejada. Problematizar o que deu certo e errado não para encontrar os culpados e apontar os indisciplinados, mas para perceber a complexidade das relações sociais vividas e a interdependência dos eventos.

Não é incomum professores recolherem o relatório escrito e simplesmente colocar um visto. Essa postura informa ao aluno a pouca importância do seu trabalho de escrita, mas também a pouca importância do museu visitado. Uma atividade simples e rápida de ser 
realizada em sala de aula tendo por base os relatórios individuais é a construção de um relatório coletivo. Com base em respostas orais dos alunos o professor pode anotar no quadro o que seria um texto síntese da visita ao museu. Para esta atividade as perguntas do professor podem retomar os horários de saída e chegada, os objetos que foram observados, as atividades realizadas em diferentes momentos da visita.

Caso o professor tenha construído com a turma as fichas de observação elas também podem ser utilizadas para retomar as informações históricas que estão em estudo pela turma. Com base nos dados que foram coletados dos objetos da exposição é possível elencar e discutir as relações destes com as informações do livro didático, com o conteúdo histórico estudado em sala de aula. Uma variação desta proposta é formar grupos responsáveis por confeccionar cartazes ou apresentações sobre temas ou abordagens específicas.

Caso tenha sido viabilizado o registro por meio de fotografias é possível solicitar, ou providenciar, que cada aluno imprima uma ou mais fotos da visita. Estas fotos podem ser utilizadas para provocar narrativas sobre a atividade ou mesmo para serem trocadas entre a turma. Uma atividade interessante é propor que cada aluno mostre ao grupo a foto de um objeto e comente as informações que possui deste objeto. Também é possível construir coletivamente um painel com fotos ilustrando os conteúdos estudados.

Independente de qual seja o produto final construído o importante é que a sua confecção se utilize de elementos e informações produzidas nas diferentes etapas deste planejamento: o momento anterior a visita e o momento posterior. E aponte para um produto concreto, seja ele um texto, um cartaz, uma página de internet ou mesmo uma apresentação teatral. Uma atividade mais elaborada é a montagem de uma exposição na escola com os registros da visita. Nesta exposição podem aparecer as informações históricas em estudo, mas também os registros realizados, as fotos, as fichas de observação, os textos produzidos. O sentido deste momento é utilização na escola da própria linguagem museológica como suporte para a comunicação do que foi vivido e aprendido durante a atividade. Desta forma não apenas se finaliza uma atividade como se desperta em outros grupos o interesse por futuras visitas ao museu.

O museu na sala de aula

"O educador democrático não pode negar-se o dever de, na sua prática docente, reforçar a capacidade crítica do educando, sua curiosidade, sua insubmissão. Uma de suas tarefas primordiais é trabalhar com os educandos a rigorosidade metódica com que devem se 'aproximar' dos objetos 
cognoscíveis. E esta rigorosidade metódica não tem nada que ver com o discurso 'bancário' meramente transferidor do perfil do objeto ou do conteúdo. É exatamente neste sentido que ensinar não se esgota no 'tratamento' do objeto ou do conteúdo, superficialmente feito, mas se alonga à produção das condições em que aprender criticamente é possível.” (Freire, 1996, p. 26)

Ao longo do texto esperamos ter deixado claro que é possível trazer o museu e seus objetos para dentro da sala de aula. Este movimento, contudo, exige o que Paulo Freire chama de "rigorosidade metódica," uma postura consciente, uma conduta planejada de quem deseja produzir situações onde a leitura do objeto museológico não se limite a decodificação, onde o estudo das informações da exposição não se confunda com a memorização, e o pensar sobre o passado não se limite a repetição do que já se sabe.

Um bom planejamento é mais que uma prescrição das atividades que serão realizadas ou um texto escrito a ser entregue a burocracia. O planejamento de ensino é uma ferramenta de reflexão sobre a prática pedagógica que será realizada. Ao colocar no papel os objetivos da ação, dos conteúdos focados e dos procedimentos a serem realizados estamos materializando na escrita nossa concepção sobre o significado da prática pedagógica. É no momento da escrita que verificamos a coerência da atividade com nossas intenções e nos defrontamos com os limites concretos para a sua realização.

Nossa proposta é que a atividade didática com o museu não se limite ao momento da visita. Ao contrário o museu pode e deve ser colocado no interior da sala de aula e utilizado como recurso didático para o ensino de história. Os museus sempre foram pensados como espaço de aprendizagem, uma aprendizagem mediada pelo objeto, uma aprendizagem amparada na concretude do objeto cultural, das relações sociais existentes no tempo e no espaço. Suas exposições estão aguardando quem esteja disposto a interpretá-las.

Para isso é preciso superar a ideia de que a vista ao museu se encerre em si mesmo. Ao contrário faz-se necessário um projeto didático que estabeleça atividades que se iniciem na sala de aula antes da visita, que se desdobre em ações concretas durante a visita ao museu, e volte à sala de aula como informação qualificada a ser confrontada com os demais recursos didáticos. Ou seja, um planejamento que possibilite que as informações do museu e da sala de aula se completem.

Defendemos que uma ação educativa que envolva escola e museu deve focar não apenas das informações históricas específicas. Ela deve prever o uso de conceitos históricos e a aplicação de procedimentos de pesquisa. Deve ainda promover a sensibilização dos estudantes sobre o papel dos museus como lugares de memória na sociedade contemporânea. 
Estas atividades de ensino devem mobilizar os estudantes para as necessidades de aprendizagem disciplinar, mas também para as possibilidades de fruição presentes no interior de qualquer museu e assim possibilitar o enriquecimento cultural dos estudantes.

\section{Referências}

ABUD, Kátia Maria, SILVA, André Chaves de Melo, ALVES, Ronaldo Cardoso. Ensino de História. São Paulo: Cengage Learning, 2010.

ALMEIDA, Adriana Mortara, VASCONCELOS, Camilo de Mello. Por que visitar museus. In: BITTENCOURT, Circe. O saber histórico na sala de aula. $11^{\mathrm{a}}$ Ed. São Paulo: Contexto, 2008. pp. 104-116.

BARBOSA, Ana Maria. Arte-educação pós-colonialista no Brasil: aprendizagem triangular. Comunicação e Educação, São Paulo, 21: 59 a 64, jan./abr. 1995. p. 63.

BITTENCOURT, Circe Maria Fernandes. Ensino de História: fundamentos e métodos. São Paulo: Cortez, 2004.

CANDAU, Vera Maria Ferrão. A didática em questão. Petrópolis: Vozes, 1984.

CHOAY, Françoise. A alegria do Patrimônio. São Paulo: Estação da Liberdade: UNESP, 2006.

COMENIUS, Jonh Amos. Didáctica Magna: a arte universal de ensinar tudo a todos. Rio de Janeiro: Martins Fontes, 2006.

FONSECA, Selva Guimarães. Didática e prática de ensino de história. Campinas, SP: Papirus, 2003.

FREIRE, Paulo. Pedagogia da autonomia: saberes necessários à prática pedagógica. São Paulo: Paz e Terra, 1996.

HARTOG, François. Tempo e Patrimônio. Varia História, Belo Horizonte: UFMG, vol. 22, no 36: pp.261-273, Jul/Dez 2006.

HORTA, Maria de Lourdes Parreiras, GRUMBERG, Evelina, MONTEIRO, Adriane Queiroz. Guia Básico de Educação Patrimonial. Brasília: Instituto do Patrimônio Histórico e Artístico Nacional, Museu Imperial, 1999.

JULIÃO, Letícia. Apontamentos sobre a história do museu. In: CADERNO de diretrizes museológicas. Brasília: IPHAN, 2006. pp. 19-32. p. 29.

LEWIS, Geoffrey. O papel dos Museus e o código de ética. In: ICOM/UNESCO. Como gerir um museu: um guia. Paris/FR: ICOM/Unesco, 2004. pp. 1-16. Disponível em:

$<$ http://icom.museum/qui-sommes-nous/la-vision/definition-du-musee/L/2.html $>$. Acesso em: 26/11/2011. 
LIBÂNEO, José Carlos. Didática. 28. ed. São Paulo: Cortez Editora, 1990.

MENEZES, Ulpiano Toledo Bezerra de. De teatro da memória ao laboratório da História: a exposição museológica e o conhecimento histórico. Anais do Museu Paulista. São Paulo, v. 35, pp. 9-42. Jan/dez 1994.

PACHECO, Ricardo de Aguiar. De como o Memorial da UFRPE fala do Ensino, Pesquisa e Extensão. Museologia e Patrimônio. Rio de Janeiro: Museu de Astronomia e ciências afins, v. 3, p. 56-62, 2011.

PACHECO, Ricardo de Aguiar. Educação, memória e patrimônio: ações educativas em museu e o ensino de história. Revista Brasileira de História (Impresso). São Paulo: ANPUH, v. 30, n. 60, pp. 143-154, 2010.

PACHECO, Ricardo de Aguiar. O ensino de história com base na Educação Patrimonial e no Estudo do Meio. Cadernos do CEOM. Chapecó/SC: UNOCHAPECÓ, v. 31, pp. 145-155, 2010b.

PIAGET, Jean. A noção de tempo na criança. Rio de Janeiro: Record, 2002.

RAMOS, Francisco Régis Lopes. A danação do objeto: o museu no ensino de história. Chapecó: Argos, 2004.

RUSEN, Jorn. A razão Histórica: teoria da história: fundamentos da ciência histórica. Brasilia: UnB, 2001.

SILVA, Tomaz Tadeu. Documentos de identidade: uma introdução as teorias do currículo. Belo Horizonte: Autêntica, 2007.

SIMAN, Lana Mara de Castro, COSTA, Carina Martins, NASCIMENTO, Silvana Sousa do. Escola e Museus: diálogos e práticas. Belo Horizonte: Secretaria de Estado da Cultura/ Superintendência de Museus; Pontifícia Universidade Católica de Minas Gerais/ Cefor, 2007.

ZABALA, Antoni. A prática educativa: como ensinar. Porto Alegre: Arte Med, 1998. 